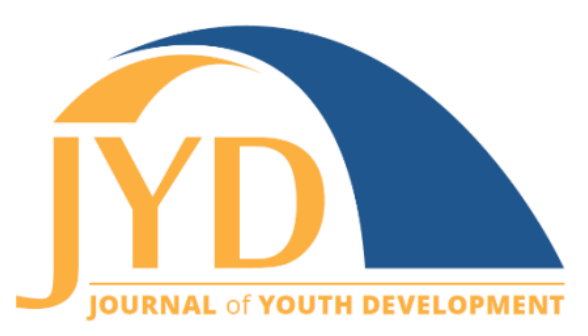

http://jyd.pitt.edu/ | Vol. 16 Issue 2-3 DOI 10.5195/jyd.2021.1153 | ISSN 2325-4017 (online)

\title{
Correction to: Banati, P., \& Bacalso, C. "Adolescent Well-Being Gap Maps: What We Know and Opportunities for Future Research." Journal of Youth Development, 16(2-3) 2021. https://doi.org/10.5195/jyd.2021.1025
}

\author{
Kate Walker \\ University of Minnesota \\ kcwalker@umn.edu \\ Abstract
}

There was a mistake in the spelling of the second author's first name in the metadata only. Christina should be spelled Cristina. The PDF of the original article is correct, and the updated metadata can be found via the DOI: https://doi.org/10.5195/jyd.2021.1025.

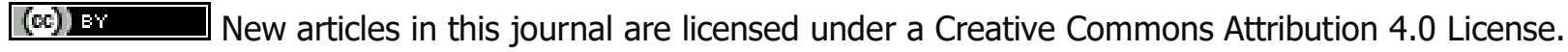

This journal is published by the University Library System, University of Pittsburgh and is cosponsored by the University of Pittsburgh Press. The Journal of Youth Development is the official peer-reviewed publication of the National Association of Extension 4-H Agents and the National AfterSchool Association. 